\title{
Boundary-layer anemometry by optical remote sensing for wind energy applications
}

\author{
Stefan EMEIS*1, Michael Harris ${ }^{2}$ and Robert M. BANTA ${ }^{3}$ \\ ${ }^{1}$ Institut für Meteorologie und Klimaforschung - Atmosphärische Umweltforschung (IMK-IFU) \\ Forschungszentrum Karlsruhe GmbH, Garmisch-Partenkirchen, Germany \\ ${ }^{2}$ QinetiQ, Malvern, United Kingdom \\ ${ }^{3}$ NOAA/ESRL, Boulder, Co, USA
}

(Manuscript received October 31, 2006; in revised form April 3, 2007; accepted April 3, 2007)

\begin{abstract}
The effective use of wind energy requires precise wind speed measurements. However, there is a risk that existing in-situ techniques with cup anemometers mounted on masts will exceed mechanical and financial limits at future hub heights. Ground-based optical remote sensing methods that measure the vertical profile of wind speed up to several hundred metres height may be a solution to these problems. This review paper will discuss the basic principles of anemometry by remote sensing and will present some optical methods in more detail.

Zusammenfassung

Die effiziente Erzeugung von Windenergie benötigt präzise Windmessungen. Die zur Zeit gebräuchliche Messtechnik mit Schalenkreuzanemometern wird jedoch bei zukünftigen Nabenhöhen an mechanische und finanzielle Grenzen stoßen. Bodengestützte optische Fernmessverfahren, die das Windprofil bis in einige hundert Meter Höhe messen, könnten eine Lösung für diese Probleme sein. Dieser Übersichtsartikel diskutiert die Grundprinzipien der Fernmessung des Windprofils und stellt einige optische Verfahren genauer vor.
\end{abstract}

\section{Problems}

Wind-energy applications require accurate measurement of wind speed and turbulence. The location of windenergy sites ("wind farms") as well as the siting of individual turbines depends on accurate measurements, because of the strong dependence of available energy on wind speed, i.e., the power derived from the wind is proportional to the cube of its speed. During operations optimum turbine performance may also depend on adjusting rotor settings to accommodate temporal changes in the nonstationary wind direction or speed that may occur, especially in the night-time stable boundary layer. As another more extreme example, certain frequencies of atmospheric turbulence can be in resonance with the fundamental frequencies of the rotor blades, causing the blades to "ring." Although such turbulence episodes occur only rarely, they can cause significant damage to hardware components of the turbines (KELLEY et al., 2005). Detection of such turbulence bursts in real time could be of great advantage to turbine operation. Also potentially harmful to wind energy converters are strong vertical gradients of wind speed and turbulence, which

\footnotetext{
* Corresponding author: Stefan Emeis, Institut für Meteorologie und Klimaforschung - Atmosphärische Umweltforschung (IMK-IFU) Forschungszentrum Karlsruhe GmbH, Kreuzeckbahnstr. 19, 82467 Garmisch-Partenkirchen, Germany, e-mail: stefan.emeis@imk.fzk.de
}

can occur under certain meteorological conditions (e.g. inversions or low-level jets). Current turbine technology generally employs blades with diameters of 60 to $110 \mathrm{~m}$ attached to their hub at heights of 70 to $100 \mathrm{~m}$. Because wind speed generally increases with height in the layer occupied by turbines, future turbines are being designed to be larger and reach higher, with diameters extending to $125 \mathrm{~m}$, and hub heights to $120 \mathrm{~m}$. The requirement for accurate wind-speed measurements thus extends above the surface to $\sim 200 \mathrm{~m}$. Operationally, data availability at intervals of minutes is needed to monitor changes in wind speed in nonstationary nocturnal flows, but detection of potentially harmful turbulence would require measurements to be available in real time at intervals of seconds. Wind measurements for wind energy purposes have been performed so far mainly with cup anemometers. After diligent calibration based on producing correct turbulence intensities, these devices deliver precise wind data (KRISTENSEN, 1999). However, due to the size of the anemometer, these measurements are representative of a quite small air volume only. The cross-section perpendicular to the mean wind direction is about six orders of magnitude smaller than the rotor area of today's wind turbines. Additionally, the wind direction can not be measured by cup anemometers. A further disadvantage of in-situ techniques is the necessity of erecting tall towers or masts (at least up to the 
hub height) for the measurement campaigns. The installation of such masts is very costly and time-consuming and needs permits from the respective authorities. Additionally, tall towers have larger cross-sections than small masts, so that the influence of towers on the measurements increases with hub height. Moreover, cup anemometers cannot measure the vertical wind component separately. The magnitude of this wind component, which can influence the wind measurements with some types of cup anemometers (KRISTENSEN, 1999), increases with hub height. Further, it is not clear whether cup anemometers and wind turbines react equally to vertical wind components. Therefore, the separate measurement of this component is desirable. Finally, since calibration is based on turbulence intensity, which often decreases with height, cup anemometers will tend to yield too low wind speed values at higher altitudes, if they have been calibrated for the higher turbulence intensities found closer to the surface.

\section{Remote sensing methods}

The aforementioned disadvantages and problems with in situ wind measurement techniques can be avoided by applying remote sensing techniques. Unlike cup anemometers that are directly driven via their interaction with the moving air, remote sensing instruments perform wind speed measurements without affecting the flow. Remote sensing is an indirect method; the received signal has to be processed for conversion into wind speed information. All available techniques depend upon transmitting a well-defined acoustic or electromagnetic beam that is partly backscattered from the atmosphere. Acoustic pulses from a sodar having a typical wavelength of about $10 \mathrm{~cm}$ are reflected by turbulenceinduced temperature fluctuations and strong temperature gradients in the atmosphere. Electro-magnetic signals of the same wavelength from radar wind profilers are scattered primarily by turbulence-induced moisture fluctuations. Pulses from weather radars, which have wavelengths that are about one to two orders of magnitude shorter, are scattered by rain drops or other hydrometeors. Optical signals from wind lidars, whose wavelength is even smaller by another three orders of magnitude, will be scattered by naturally-occurring dust particles, ice crystals, or water microdroplets (aerosols) suspended in the air by viscous forces (Mie scattering) or from air molecules (Rayleigh scattering). The (radial) wind component along the line of sight can be derived from the Doppler shift, which is the frequency difference between the emitted and the backscattered signal. This frequency shift is proportional to the ratio of the wind speed and the propagation speed of the detecting signal. The deduction of wind speed from the Doppler shift therefore follows directly via well-established physical principles.
However, the electronics of the instrument needs calibration, and disturbing influences such as ground clutter may have to be taken into account. The distance between the instrument and the scattering air volume is usually determined from the signal round-trip travel time. If all three components of the wind have to be measured then successive velocity-component profiles have to be made in at least three different directions shortly after each other. The wind components can subsequently be computed from the radial velocities by applying trigonometric relations. Sodars and wind profilers perform these three-dimensional wind soundings by emitting upward three to five beams inclined to each other by about $15^{\circ}$ to $20^{\circ}$. Radars and lidars usually make conical scans around the zenith with comparable aperture angles. This scanning mode is also called VAD (velocity-azimuth-display) mode (BROWNING and WEXLER, 1968; BANTA et al., 2002). For calculation of a mean wind, it has to be assumed that the wind field is homogeneous over the horizontal distance enclosed by the beams or the conical scan. Thus, remote sensing methods due to their design yield values that are representative of larger air volumes. This fact hampers the direct intercomparison with cup anemometer data in locations where the wind flow is non-uniform over the region of space encompassed by the mast and lidar scan, but on the other hand remote sensing methods are very likely more suited for wind energy applications because the air volume scanned by the measurement device and the air volume which passes through the rotor plane of a wind turbine are of comparable size. Initially, remote sensing of wind was mainly done with acoustic methods (sodar), because the speed of sound which is only one to two orders of magnitude larger than the wind speed leads to relatively large Doppler shifts that are easily detectable (NEFF and COULTER 1986). Additionally this method offers a high vertical resolution $(5$ to $10 \mathrm{~m})$ and a small lowest range gate (10 to $30 \mathrm{~m}$ ). Thus the technical and electronic obstacles to be overcome for the application of the acoustic method are considerably lower and cheaper than for the respective optical and electromagnetic methods. The advantages are neutralised by the limited data availability of the acoustic method. In fact, none of the remote sensing methods (sodar, radar wind profiler, wind-lidar) can guarantee a one hundred percent data availability due to the backscattering properties of the atmosphere. The strongest limitation by atmospheric conditions with respect to wind measurements is found with the weatherradar technique that delivers reasonable data only in case of rain, although under limited conditions signals from insects or index-of-refraction turbulence have been used in clear-air boundary-layer studies. A sodar fails in situations with missing turbulence and low temperature gradients. These situations lead quite often to a low range of 
a sodar around dawn and dusk (MAUGHAN et al., 1982; EMEIS et al., 2004). A radar wind profiler usually suffers from very dry air masses only, and the lidar technique is hampered by strong rain, fog, and clouds. An advantage of optical remote sensing methods is the ability to focus the transmitted light beam because the wave length of light is several orders of magnitude smaller than the aperture of the sensing instrument. Thus the effects of diffraction are similarly reduced in magnitude. Side lobes which are characteristic of the other three sensing methods do not appear, and lateral shielding is not necessary. Optical methods have no negative influence on the environment. They do not produce noise or electromagnetic stray fields and they are not affected by these disturbances. Until recently optical methods, like electromagnetic methods, had the disadvantage of a quite low range (and hence also height) resolution of about $50 \mathrm{~m}$ and large lowest range gates of several hundreds of metres. For example, a commercially available solidstate system operates at a minimum range of $\sim 400 \mathrm{~m}$ with range gates that could be as low as $50-75 \mathrm{~m}$ (HANNON, 2004). The range resolution is limited by the pulse duration, which cannot be minimised unboundedly since there is a direct trade-off against the velocity resolution. The lowest range gate is caused by the unavoidable switching between transmitting and receiving. A larger lowest range gate also helps to safeguard the instrument against blinding by extremely high backscatter intensities from nearby reflecting objects. Acquisition of VAD conical scan data at low elevation angles leads to a partial compensation for the poor height resolution, but this in turn is achieved at the expense of an even larger measurement volume. These drawbacks had until recently limited the use of optical remote sensing techniques for wind speed mainly to the determination of wind shear at airports (see also VDI 3786-14; HANNON, 2004, and CHAN and Shao, 2007). A comparison between the mentioned commercially available system and a radar wind profiler can be found in VOGT and WIESER (2006). In the meantime, enhancements in laser technology, in electronic signal processing, and innovative means of range determination for backscattered signals have decreased these problems. As a consequence, optical wind measurement techniques have recently become more suited to the requirements of wind-energy applications. Furthermore, the usage of infrared light makes this technology eye-safe, a mandatory requirement for an automatic measurement technique running unattended for longer time periods. In the following, currently available optical remote sensing methods based on the analysis of the Doppler shift are presented. Different methods for range determination will be addressed. Finally, other optical flow measurement techniques will be briefly introduced.

\subsection{Doppler wind lidar}

\subsubsection{Range determination by signal delay}

Range-resolved remote sensing systems transmit signals in pulses, which are then scattered by atmospheric inhomogeneities or suspensions (e.g., aerosol, droplets), sending a small fraction of the transmitted energy back to the receiver, as outlined in the previous section. Distance to the measurement volume is determined from the time of flight of the signal pulse. Overviews of the state of the art of lidar techniques for wind and turbulence measurement using signal delay for the range determination have been given by HARDESTY and DARBY (2005) and DAVIES et al. (2003). Two common approaches to determining the frequency of the return signal for Doppler analysis are coherent (heterodyne) detection and direct (or "incoherent") detection, which will be described in this section.

\subsubsection{Mie scattering: Coherent Doppler lidar}

Coherent or heterodyne detection of wind speeds using Doppler lidar relies on the ability to generate two signals having a precise offset in frequency. The signal transmitted to the atmosphere comes from a primary laser, variously called a "master oscillator" (MO), a "pulse laser" (GRUND et al., 2001), or a "power oscillator" (PO; e.g., POST and CuPP, 1990). Generally the second or reference signal comes from a second, low-power, continuous-wave laser, or "local oscillator" (LO), although in some systems the frequency difference is produced by splitting the signal from the MO and offsetting the frequency of one of the two resulting signals. The wavelength of coherent lidars has typically been in an eye-safe region of the infrared spectrum, between $1.5 \mu \mathrm{m}$ (solid-state lasing source) and $10.6 \mu \mathrm{m}\left(\mathrm{CO}_{2}\right.$ source), where atmospheric scattering is dominated by aerosol. In a coherent lidar receiver the backscattered return signal from the atmosphere is optically mixed with the coherent reference-frequency radiation from the $\mathrm{LO}$ at the system detector. The detector senses the beat frequency between the return signal and the reference signal (heterodyne detection), and the Doppler shift is calculated from this beat frequency. A detailed description of the configuration, design characteristics, tradeoffs, and data processing issues of a coherent Doppler lidar system is provided in GRUND et al. (2001).

Because of the sensitivity of coherent lidar systems, they can be made relatively compact, yet maintain useful performance standards, including maximum ranges (several kilometers to $\sim 20 \mathrm{~km}$ ), range resolution (less than $100 \mathrm{~m}$ ), and velocity precision (a few 10's of $\mathrm{cm}$ $\mathrm{s}^{-1}$ ). Such systems have a very narrow beam, which allows sampling close to the Earth's surface, including 


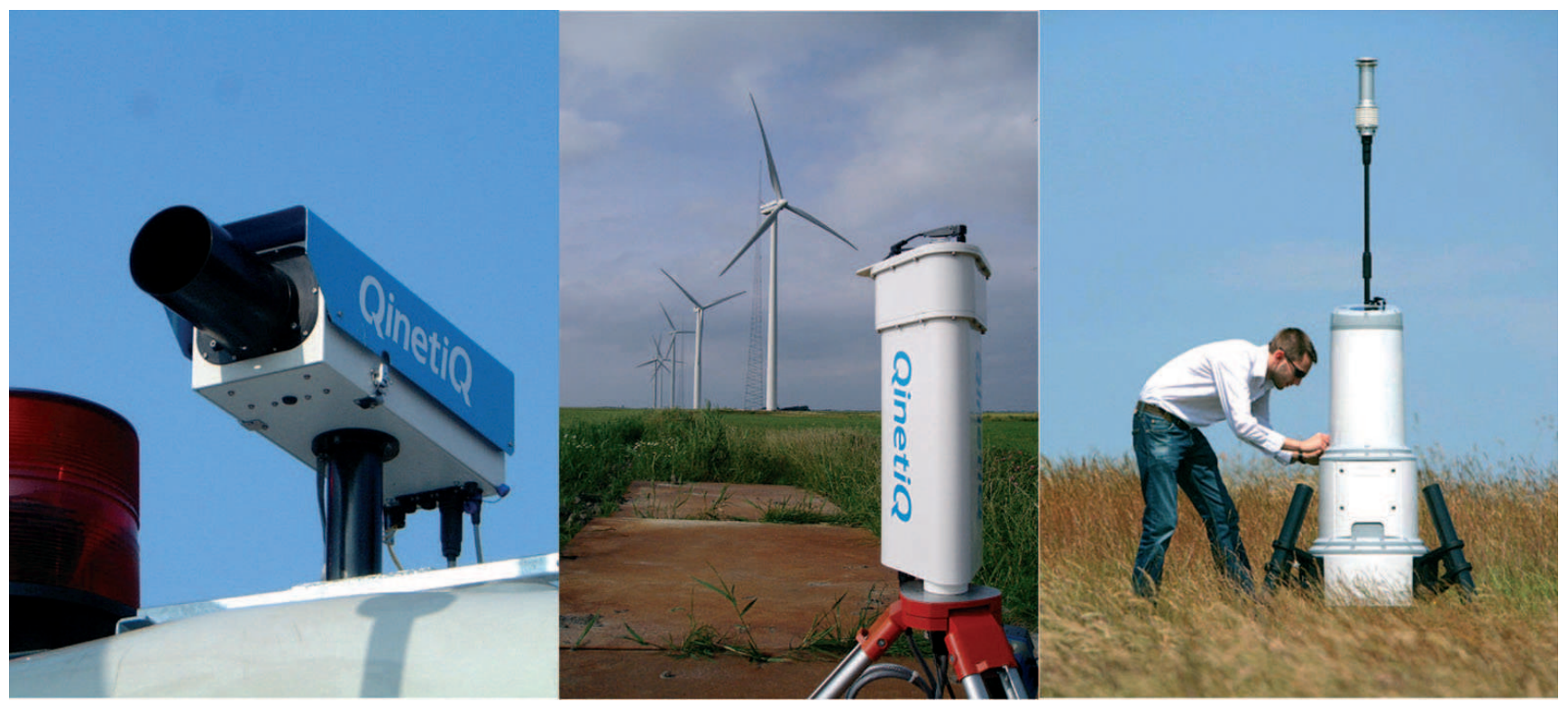

Figure 1: Stages of evolution of the ZephIR lidar. The left-hand frame shows the lidar head mounted on the nacelle of a Nordex N-90 wind turbine. The middle frame shows the prototype ground-based wind profiler at Ris $\emptyset$ wind energy test site, Høvsøre, Denmark. The right-hand frame shows the ZephIR production model deployed in the field.

near topography and buildings. Because of these capabilities, they are well suited for atmospheric boundarylayer applications, including wind energy.

\subsubsection{Rayleigh scattering: Incoherent Doppler lidar}

An incoherent (or "direct detection") Doppler lidar (CANIN et al., 1989) is an alternative for the measurement of atmospheric wind speeds in air masses with low or vanishing aerosol loads. These pulsed systems usually operate in the UV and rely on contributions from both aerosol and the enhanced molecular (Rayleigh) scattering at shorter wavelength to provide the return signal. A Fabry-Perot interferometer (ABREU et al., 1992) can be used to analyse the Doppler shift of the Rayleigh backscatter. While the capabilities of incoherent lidar are impressive (they are being considered for space-based global wind measurements), their current size, cost, and complexity suggest the technique is inappropriate for wind energy applications considered here (HARRIS et al., 2006).

\subsubsection{Range determination by beam focusing}

Recently the British company QinetiQ has designed and built a transportable wind lidar ("ZephIR", Fig. 1) measuring in the near infrared at a wavelength of $1.575 \mu \mathrm{m}$. This instrument is about $1.5 \mathrm{~m}$ high and weighs $150 \mathrm{~kg}$. It exploits recent developments in optical fibre and related components from the telecommunications industry in order to simplify the alignment and construction of the interferometer that forms the core of the lidar. The system emits a continuous-wave $(\mathrm{CW})$ beam, and interrogation of the wind speed at a given range is achieved by focusing, rather than by the time-of-flight method of pulsed systems. The system cannot distinguish between air motion towards and away from the lidar, and this leads to an ambiguity of 180 in the derived value of wind direction. This is easily resolved with reference to a simple wind vane measurement at a height of a few metres. Several different measuring heights between 5 and $150 \mathrm{~m}$ above ground can be programmed. The profile of the three-dimensional wind vector is yielded by scanning a cone with $30^{\circ}$ half angle once per second (BANAKH et al., 1995). Hence the diameter of the measurement volume is $173 \mathrm{~m}$ at $150 \mathrm{~m}$ height. The probe length increases roughly as the square of the height; as an example the vertical resolution is $\sim \pm 10 \mathrm{~m}$ at $100 \mathrm{~m}$ height. Strong reflections from particles and other moving objects outside the focal range (e.g. due to smoke, fog or birds) can lead to spurious Doppler returns (HARRIS et al., 2001), but these effects can be recognised and mitigated by signal processing techniques. An intercomparison exercise with cup anemometers at heights between $40 \mathrm{~m}$ and $100 \mathrm{~m}$ above ground on the test range of the Danish research centre Ris $\varnothing$ in Høvsøre has yielded very good agreement (see Fig. 2 and SMiTH et al., 2006), and further comparisons performed by other groups around the world are yielding similar results in a wide range of terrain types, both onshore and offshore. The compactness of these new lidar systems also opens the potential to measure horizontally oncoming gusts upstream of a wind turbine at hub height. This capability was first successfully demonstrated in a proof-of-principle experiment in 2003, in which a QinetiQ lidar was mounted on the nacelle of 
Lidar / Cup @ 100m, 21 august 2004

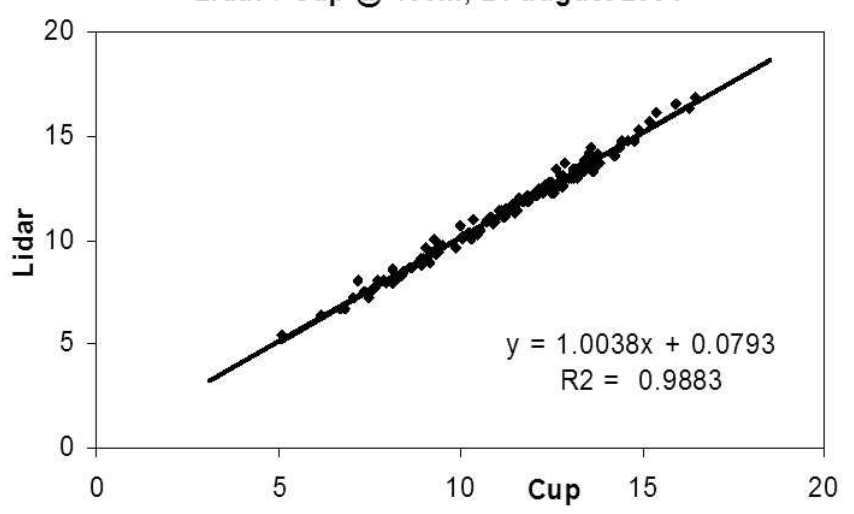

Figure 2: Regression plot of 10-minute averaged windspeed $100 \mathrm{~m}$ above ground in $\mathrm{m} / \mathrm{s}$, measured by the Zephir lidar and a calibrated cup anemometer mounted at the Høvsøre mast. The lidar was situated $120 \mathrm{~m}$ from the base of the mast. The measurements were obtained over a $24 \mathrm{hr}$ period when there was little risk of shadowing of the cup (by the mast itself, or by adjacent turbines). The corresponding plots at other heights $(40 \mathrm{~m}, 60 \mathrm{~m}, 80 \mathrm{~m})$ display similarly good agreement and correlation. This is taken from the paper SMITH et al. (2006).

a Nordex N90 turbine (HARRIS et al., 2006). Due to the high data rate of $10 \mathrm{~Hz}$, the short interruptions of the beam by the blades of the turbine did not impede the measurement. A wind speed of $15 \mathrm{~m} / \mathrm{s}$ and a focusing of the beam at $150 \mathrm{~m}$ distance permits a warning time of 10 seconds in order to adapt the turbine. With $25 \mathrm{~m} / \mathrm{s}$ wind speed the warning time is $6 \mathrm{~s}$, still considerably longer than the timescale for blade pitch adjustment. More research is needed to quantify the benefit of incorporating lidar as part of the turbine control system; such a scheme might involve staring directly upwind, but it could also employ a scan pattern in order to probe a wider area in front of the blades. A similar lidar system has also been installed in a rearward-looking configuration on a test turbine by Ris $\varnothing$ (BINGÖL, 2005); a programmable scanner permits examination of turbine wake behaviour in space and time.

\subsubsection{Optical coherence tomography for range determination}

In addition to signal delay and beam focusing further attempts have been made to enhance the range resolution of optical remote sensing. One approach is to use optical coherence tomography which has been applied quite successfully in medical examinations (FERCHER et al., 2003). This research (BENNETT and Christie, 2007; BENNETT et al., 2006), which has led only to single case studies but not to a viable method for meteorological purposes so far, uses a fibre-optic based continuouswave Doppler lidar. Infra-red radiation at $\lambda=1.55 \mu \mathrm{m}$ from a distributed feedback laser diode is split between a reference path and a signal path. Radiation following the signal path is amplified and transmitted towards a scattering target, whence some tiny proportion is returned to the instrument. This is then mixed in a coupler with delayed radiation that has followed the reference path. A narrow-band beat signal can only be expected when the length of the delay line matches the path length in the atmosphere to within the coherence length of the source. Scattering from other distances will give a beat signal widened by twice the linewidth of the source (HARRIS et al., 1998). In the given instrument, the linewidth of the source is $\Delta v=1.4 \mathrm{MHz}$; the coherence length for the beats signal is $\Delta r=c /(2 \pi \Delta v)=34 \mathrm{~m}$, and this should be the effective range resolution of the system. The range of the system is between $42 \mathrm{~m}$ and $217 \mathrm{~m}$. For a reliable operation the atmospheric visibility should be below 30 $\mathrm{km}$.

\subsection{Other optical flow measurement techniques}

A further method to measure wind flow that is based on aerosol backscatter is laser Doppler anemometry (LDA, DURST et al., 1976), also sometimes called laser Doppler velocimetry (LDV), which relies on the interference of two coherent laser beams. Using a beam splitter, the instrument emits two coherent beams which cross each other at some distance (probably much less than $100 \mathrm{~m}$ ) from the device. At the position of the cross-over an interference pattern is formed (the frequency of the resulting beats is also called Doppler frequency which explains the name of this measurement technique). Aerosol particles floating in the air passing through this cross-over region are alternately illuminated or in darkness. From the frequency of this intensity oscillation, the air speed perpendicular to the fringes of the interference pattern can be determined. Both velocity components can be derived with this technique by producing a second pattern turned by $90^{\circ}$ with respect to the first one. Successful boundary layer application of this technique, which has been designed primarily for wind tunnel flow measurements, has not been reported. Most probably the sensitivity at longer ranges is not sufficient for this purpose in the unseeded atmosphere. Particle imaging velocimetry (PIV; ADRIAN, 1991) is another method commonly used for flow measurement in wind tunnels. Like LDA, it requires careful seeding of the flow with particles or oil droplets and is therefore unsuitable for remote sensing in the atmosphere. The same comments also apply to the technique of Doppler Global Velocimetry (DGV, MEYERS, 1995).

\section{Examples of Doppler lidar applications to wind energy issues}

Up to now only a few studies exist, which report on optical wind measurements for wind energy issues. Most 

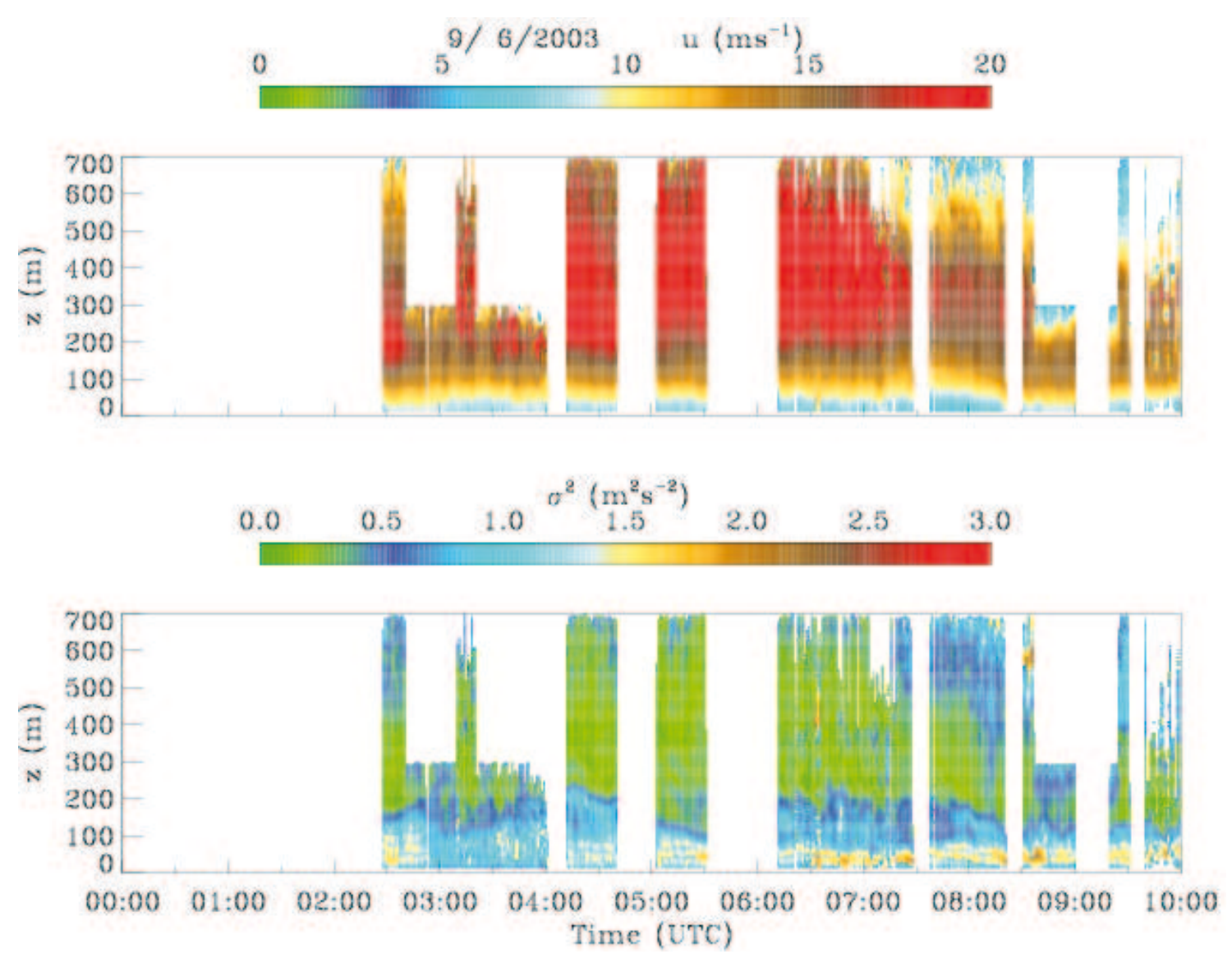

Figure 3: Example of time-height cross section of nocturnal wind speed (top panel) and variance (lower panel) for September 6, 2003, 01 to $11 \mathrm{UTC}$.

of the studies to date have employed coherent Doppler lidars, which have proven well suited to address problems on time and space scales of relevance to wind energy. One example has been the application of the scanning High-Resolution Doppler Lidar (HRDL) recently developed at the Earth System Research Laboratory of the U.S. National Oceanic and Atmospheric Administration (NOAA/ESRL; formerly Environmental Technology Laboratory). HRDL operates at $2.02 \mu \mathrm{m}$ in the infrared part of the light spectrum, has a first range gate of data at $\sim 200 \mathrm{~m}$ range, a range resolution of $30 \mathrm{~m}$, and a velocity precision evaluated at $\sim 20 \mathrm{~cm}$ $\mathrm{s}^{-1}$ (GRUND et al., 2001; WULFMEYER et al., 2000). The wind-energy-related measurements were taken in the U.S. Great Plains, where a major contribution to the wind resource is a recurrent nocturnal southerly lowlevel jet (LLJ) that is prevalent during the warm season. Important properties of the LLJ are its speed and height, the speed and shear across the height interval spanned by the rotors, and the magnitude and frequency of turbulence in the rotor layer. These properties were investigated using HRDL at two locations, southeast Kansas during the Cooperative Atmosphere-Surface Exchange Study campaign of October 1999 (CASES-99: BANTA et al., 2002, 2003; POulOs et al., 2002) and in south- east Colorado, south of the town of Lamar, during the Lamar Low-Level Jet Project (Kelley et al., 2004, 2005; Pichugina et al., 2004, 2005) in September 2003 (LLLJP-03). In the months immediately following the Lamar deployment, more than 100 wind turbines were installed at the site of LLLJP-03.

The usefulness of Doppler lidar for several aspects of wind energy applications has been demonstrated using data from these projects. Mean wind profiles were determined using azimuth (conical) scans and elevation scans (which produce a vertical slice of data in the atmosphere and which were generally performed parallel to the wind direction). Frequency distributions of mean wind properties (speed, direction) are useful for site assessment of wind-energy potential (BANTA et al., 2002; PICHUGINA et al., 2004, 2005). Another property of the wind profile is the power-law exponent often used to extrapolate wind-profile data to altitudes above which measurements were taken. Distributions of this quantity determined by PICHUGINA et al. (2004) from HRDL data show that the value of the exponent is often much larger than its assumed value of 0.2 , and that it varies with height.

In addition to the usefulness of mean-wind data for long-term site assessment, lidar profile data could also 


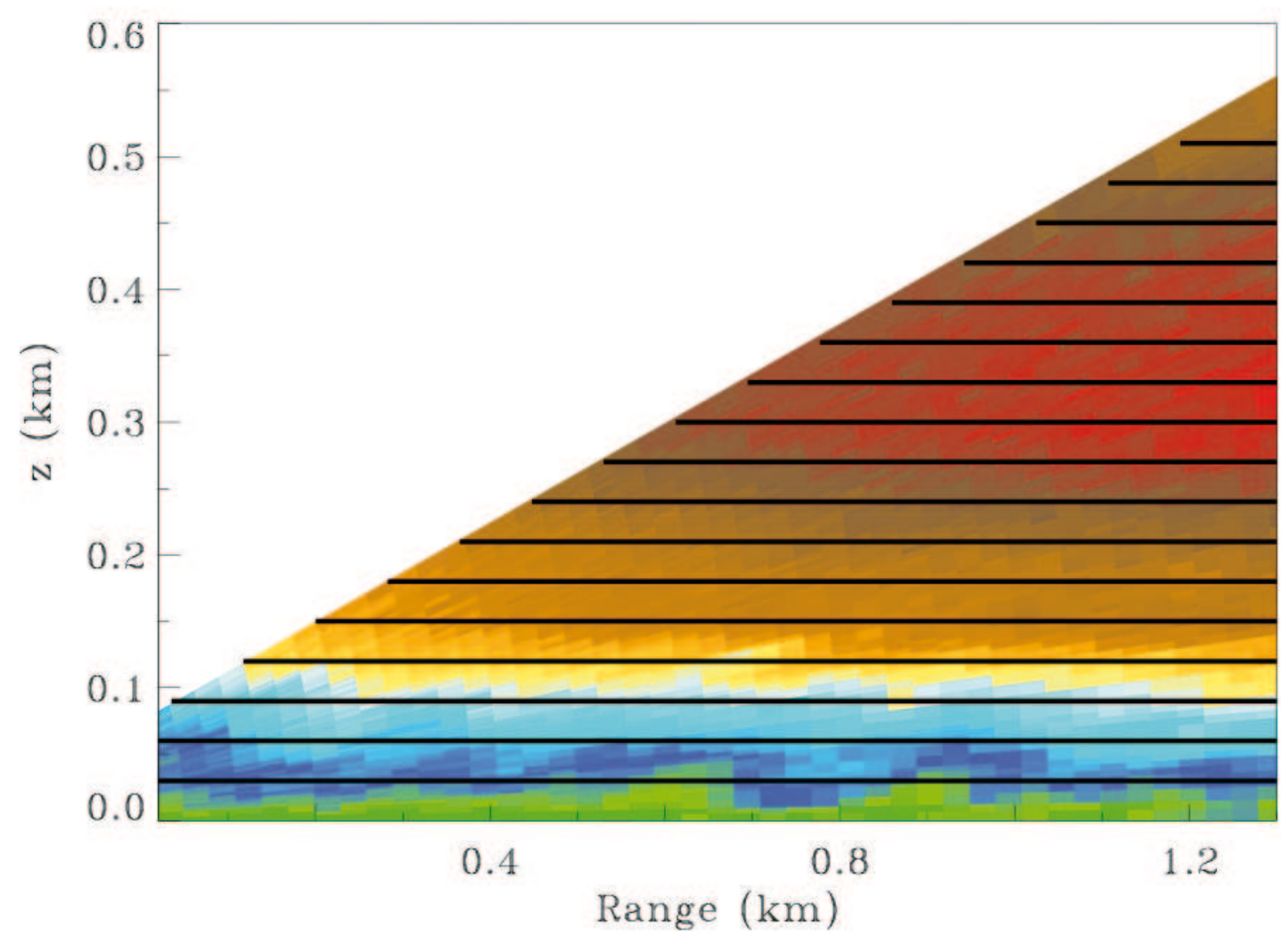

Figure 4: Example of vertical-slice scan with vertical binning (from BANTA et al., 2006).

be useful for real-time turbine operations. Spatially averaged, statistically significant profile data are available at time intervals of 2 min or less, which could be used to adjust turbine operational settings to accommodate changes in wind speed and direction. Fig. 3 shows an example of a time-height cross section of wind speed (top panel) for an entire night, constructed from such profiles. Temporal evolution of the wind profile over the night, as well as changes over shorter time intervals of less than an hour, are both evident. Although the range resolution of HRDL is $30 \mathrm{~m}$, the desired vertical resolution of $\sim 10 \mathrm{~m}$ or less can be achieved by scanning (or pointing) at lower elevation angles, or by performing elevation (vertical-slice) scans.

Over the U.S. Great Plains, BANTA et al. (2002, 2006) found that the directional shear with height was generally small when LLJs of about $12 \mathrm{~m} \mathrm{~s}^{-1}$ or more were present. Under these conditions, along-wind vertical slice scanning can be used to produce wind-speed profiles at intervals of $30 \mathrm{~s}$ or less, as used in Fig. 3. When significant directional shear is present, the wind profiles would need to be monitored using conical scans at one or more elevation angles, which may take 2 to 5 min, depending on how many elevations are used for the sampling.

Doppler lidar data at high resolution are also useful for characterizing turbulence properties of the atmosphere, either as mean statistics or as revealing turbulence events. BANTA et al. (2006) defined vertical averaging bins for sequential vertical-slice scans (Fig. 4) and calculated mean and variance profiles of the streamwise wind component. These profile statistics were composited to relate mean and turbulence profile properties to those of the LLJ. Techniques for calculating other turbulence properties have been demonstrated, including second, third and fourth moments of the vertical velocity (LENSCHOW et al. (2000), velocity structure functions and coherence (LOTHON et al., 2006), and vertical profiles of momentum and scalar fluxes (e.g., EBERHARD et al., 1989; GIEZ et al., 1999; BÖSENBERG and LINNÉ, 2002; LINNÉ et al., 2007). Several methods have also been proposed for estimating the eddy dissipation rate from Doppler lidar data (e.g., BANAKH and SMALIKHO, 1997; FREHLICH and CORNMAN, 2002; SMALIKHO et 
al., 2005), which provide information on the fine-scale turbulence. Such fine-scale information is valuable for indicating overall turbulence levels or the presence of turbulent patches. Turbulence that adversely affects turbine operation, however, occurs at preferred time scales of a few seconds, which are generally at the lowerfrequency (or lower wavenumber) end of the turbulence energy spectrum. It would therefore be desirable to characterize the features of the flow that produce the turbulent fluctuations, to determine whether those frequencies are present at high enough amplitudes to affect the turbine operations.

Data from the high-resolution lidar HRDL have proven useful in probing the behaviour of many of these kinds of atmospheric flow features or events that produce turbulence. Breaking Kelvin-Helmholtz instabilities, for example were studied by NewsOM and BAnta (2003), Blumen et al. (2001), and Poulos et al. (2002), and ducted gravity waves just above the LLJ maximum were studied by FRITTS et al. (2003). Other types of discontinuity, including those with frontal or density current structure or larger-scale propagating gravity waves, were investigated by DARBY et al. (2002) and SUN et al. (2002, 2004). These types of feature, or others of similar time and space dimensions, are probably responsible for the adverse effects of turbulent fluctuations on rotor and turbine hardware. The fact that HRDL has been able to characterize their behaviour in such detail demonstrates that real-time detection of such events is possible.

Wind energy often exploits irregularities in topography, such as speed up of flow over hills or through gaps, for optimum siting of wind-generation facilities. Doppler lidar, including HRDL and other systems with greater range, have proven capabilities to reveal the relationship between wind-flow variability and terrain. For example, localized nocturnal flows emanating from valleys or canyons emptying onto a plain were studied in Colorado (BANTA et al., 1995, 1996; LEVINSON and BANTA 1995; DARBY et al., 1999) and near Salt Lake City, Utah (BANTA et al., 2004; DARBY et al., 2006); the structure of flow within Alpine valleys was documented by DROBINSKI et al. (2001, 2003a, b); windstorm-type flow structure was noted in Colorado (CLARK et al., 1994) and to the north of the Alps in Austria (FLAMANT et al., 2002; WEISSMANN et al., 2004); and a recurrent nocturnal LLJ structure was found in the valley of the Great Salt Lake, Utah (BANTA et al., 2004). The use of Doppler lidar scan data for site assessment could replace extensive arrays of surface tower networks, with the added benefit of providing data aloft in the vertical layers occupied by the turbine rotors.

In the review by DAVIES et al. (2003), the instrument of the former British Defence Evaluation and Research Agency (DERA) that is presented in some detail uses infrared light at $10.6 \mu \mathrm{m}$ and has a range resolution of $112 \mathrm{~m}$. A possible solution for the problem of large measurement volumes due to conical scanning with these techniques may be the Dual-Doppler lidar technique. Here two identical lidars look into the same air volume from two different positions. Such an attempt using two of the abovementioned $10.6 \mu \mathrm{m}$ lidars (belonging to the University of Salford and to QinetiQ, the latter emerged out of DERA in 2001) is described in COLLIER et al. (2005). NEWSOM et al. (2005) used similar techniques to study boundary-layer eddy structure near an urban center. Both studies were directed at the improvement of urban dispersion modeling.

\section{Conclusions and outlook}

The use of optical techniques to measure the wind for wind energy purposes is still in its infancy, with currently only one established pulsed lidar system (HANNON, 2004), and one CW wind profiling instrument (QinetiQ ZephIR) recently becoming commercially available that is capable of providing the small minimum ranges and range resolutions needed for wind energy applications. Optical remote-sensing techniques have clear advantages such as high data availability, low environmental impact, and low sensitivity to disturbing external influences. Moreover, the flexibility of these techniques may offer new measurement opportunities which have not been considered with other remote sensing instruments. On the other hand the price for purchasing lidar instruments is still quite high compared to sodar (though not necessarily in comparison to a tall mast, particularly in an offshore location). In addition, there are issues associated with the limited vertical resolution, and for the determination of the three-dimensional wind vector a rather large volume averaging has to be made.

Although experiences with such instruments are still quite limited, a growing number of groups are reporting excellent performance in calibrated tests against met masts (SMith et al., 2006; Albers and SMith, 2005; KINDLER et al., 2007; PICHUGINA et al., 2007, submitted) with any discrepancy of a similar order to the inherent uncertainty of the cup anemometers (KRISTENSEN, 1999). Such comparisons must be carried out with care in order to avoid problems such as such as shadowing of the cup anemometer by the mast from certain directions, and topographic effects leading to non-uniform flow across the area occupied by mast and lidar scan (including turbine wakes). In the studies referenced above, the availability lies in the range $95 \%$ to $99.5 \%$, the gradient of the regression plots for 10-minute averaged horizontal wind speed is consistently within 0.97 to 1.03 , and the value of correlation coefficient $\left(\mathrm{R}^{2}\right)$ for unconstrained linear regression (as in Figure 4) lies between 
0.96 and 0.995 , depending on the terrain and measurement height. There is currently a need for a unified method to allow meaningful comparison between the performance of different remote sensing methods. In addition to wind resource assessment, the range of possible applications includes turbine power curve measurement, assessment of turbine wakes, and real-time gust warning for individual turbines. There is ongoing research on the extraction from lidar measurements of turbulence data relevant to the wind industry. Several field comparisons are currently underway aiming towards verification of lidar turbulence data. The next few years will reveal whether optical techniques can achieve wider acceptance in wind energy technology applications.

\section{Acknowledgements}

The contributions of the third author (RMB) were supported by the NOAA Air Quality and Health of the Atmosphere Programs. We thank Sara TUCKER, Michael HARDESTY, and Lisa DARBY for helpful comments on this manuscript, and Yelena L. PICHUGINA for figure preparation. Likewise we thank the two anonymous reviewers who helped to improve the structure of the paper.

\section{References}

Abreu, V.J., J.E. BARNES, P.B. HAYs, 1992: Observations of wind with an incoherent lidar detector. - Appl. Opt. 31, 4509-4514.

ADRIAN, R.J., 1991: Particle-imaging techniques for experimental fluid mechanics. - Ann. Rev. Fluid Mech. 23, 261.

Albers, A., D. Smith, 2005: Den Wind mit Lasern messen. - Erneuerbare Energien, 4, 36-38.

BANAKH, V.A., I.N. SMALIKHO, 1997: Estimation of the turbulent energy dissipation rate from the pulsed Doppler lidar data. - Atmos. Oceanic Opt. 10, 957-965.

BANAKh, V.A., I.N. SMALiKho, F. KÖPp, C. Werner, 1995: Representativeness of wind measurements with a cw Doppler lidar in the atmospheric boundary layer. - Appl. Opt. 34, 2055-2067.

Banta, R.M., L.D. Olivier, W.D. NefF, D.H. LeViNSON, D. RUFFIEUX, 1995: Influence of canyon-induced flows on flow and dispersion over adjacent plains. - Theor. Appl. Climatol. 52, 27-42.

BANTA, R.M., L.D. Olivier, P.H. Gudiksen, R. LANGE, 1996: Implications of small-scale flow features to modeling dispersion over complex terrain. - J. Appl. Meteor. 35, 330342.

Banta, R.M., R.K. Newsom, J.K. Lundquist, Y.L. Pichugina, R.L. Coulter, L. MAHRT, 2002: Nocturnal low-level jet characteristics over Kansas during CASES-99. - Bound.-Layer Meteor. 105, 221-252.

Banta, R.M., Y.L. Pichugina, R.K. Newsom, 2003: Relationship between low-level jet properties and turbulence kinetic energy in the nocturnal stable boundary layer. - J. Atmos. Sci. 60, 2549-2555.
Banta, R.M., L.S. DARby, J.D. FASt, J.O. Pinto, C.D. Whiteman, W.J. SHAw, B.D. ORR, 2004: Nocturnal low-level jet in a mountain basin complex. Part I: Evolution and implications to other flow features.- J. Appl. Meteor. 43, 1348-1365.

Banta, R.M., Y.L. Pichugina, W.A. Brewer, 2006: Turbulent velocity-variance profiles in the stable boundary layer generated by a nocturnal low-level jet. - J. Atmos. Sci. 63, 2700-2719.

Bennett, M., S. Christie, 2007: Doppler Lidar Measurements Using a Fibre Optic System. - Meteorol. Z. 16, ISARS special issue.

Bennett, M., H. EdNER, R. GRÖnLUnd, M. SJÖHOlM, S. SVANBERG, R. FERrARA, 2006: Joint application of Doppler Lidar and differential absorption lidar to estimate the atomic mercury flux from a chlor-alkali plant. - Atmos. Environ. 40, 664-673.

BINGÖL, F., 2005: Adapting a Doppler laser anemometer to wind energy. - Masters thesis, www.afm.dtu.dk/Publications/msc.html

Blumen, W., R.M. BAnTA, S.P. BuRns, D.C. Fritts, R. Newsom, G.S. Poulos, J. Sun, 2001: Turbulence statistics of a Kelvin-Helmholtz billow event observed in the nighttime boundary layer during the CASES-99 field program. - Dynam. Atmos. Oceans, 34, 189-204.

BösenberG, J, H. Linné, 2002: Laser remote sensing of the planetary boundary layer. - Meteorol. Z. 11, 233-240.

Browning, K. A., R. WeXler, 1968: The Determination of Kinematic Properties of a Wind Field Using Doppler Radar. - J. Appl. Meteor. 7, 105-113.

Canin, M. L., A. Garnier, A. Hauchecorne, J. Porteneuve, 1989: A Doppler Lidar for Measuring Winds in the Middle Atmosphere. - Geophys. Res. Lett. 16, 1273.

Chan, P.W., A.M. ShaO, 2007: Depiction of complex airflow near Hong Kong International Airport using a Doppler LIDAR with a two-dimensional wind retrieval technique. Meteorol. Z. 16, 475-488.

Clark, T.L., W.D. Hall, R.M. BanTA, 1994: Two- and three-dimensional simulations of the 9 January 1989 windstorm: Comparison with observations. - J. Atmos. Sci. 51, 2317-2343.

Collier, C.G., F. Davies, K.E. Bozier, A.R. Holt, D.R. Middleton, G.N. Pearson, S. Siemen, D.V. Willets, G.J.G. Upton, R.I. Young, 2005: DualDoppler lidar measurements for improving dispersion models. - Bull. Amer. Meteor. Soc. 86, 825-838.

DARBY, L.S., W.D. NEFF, R.M. BANTA, 1999: Multiscale analysis of a meso-frontal passage in the complex terrain of the Colorado Front Range. - Mon. Wea. Rev. 127, 20622081.

DARBy, L.S., R. M. BANTA, W.A. BREWER, W.D. NeFF, R.D. Marchbanks, B.J. MCCARTy, C. J. SenFF, A.B. White, W.M. Angevine, E.J. Williams, 2002: Vertical variations in $\mathrm{O}_{3}$ concentrations before and after a gust front passage. - J. Geophys. Res. 107 (D13), 4321, DOI: 10.1029/2001JD000996.

Darby, L.S., K.J. Allwine, R.M. Banta, 2006: Nocturnal low-level jet in a mountain basin complex. Part II: Transport and Diffusion of tracer under stable conditions.J. Appl. Meteor. 45, 740-753. 
Davies, F., C.G. Collier, K.E. Bozier, G.N. Pearson, 2003: On the accuracy of retrieved wind information from Doppler lidar observations. - Quart. J. Roy. Meteor. Soc. 129, 321-334.

Drobinski P., A.M. Dabas, C. Haeberli, P.H. FlaMANT, 2001 : On the Small-Scale Dynamics of Flow Splitting in the Rhine Valley During a Shallow Foehn Event. Bound.-Layer Meteor. 99, 277-296.

- , - , - - 2003a: Statistical Characterization of the Flow Structure in the Rhine Valley. - Bound.-Lay. Meteor. 106, 483-505.

Drobinski P., C. HAEberli, E. Richard, M. Lothon, A.M. DABAS, P.H. Flamant, M. Furger, R. STEINACKER, 2003b: Scale Interaction Processes during MAP-IOP 12 South Foehn Event in the Rhine Valley. Quart. J. Roy. Meteor. Soc. 129, 729-754.

Durst, F., A. Melling, J.H. Whitelaw, 1976: Principles and Practice of Laser Doppler Anemometry. - London, Academic Press.

Eberhard, W.L., R.E. Cupp, K.R. Healey, 1989: Doppler lidar measurement of profiles of turbulence and momentum flux. - J. Atmos. Oceanic Technol. 6, 809-819.

Emeis, S., Chr. Münkel, S. Vogt, W.J. Müller, K. SCHÄFER, 2004: Atmospheric boundary-layer structure from simultaneous SODAR, RASS, and ceilometer measurements. - Atmos. Environ. 38, 273-286.

Fercher, A.F., W. Drexler, C.K. Hitzenberger, T. LASSER, 2003: Optical coherence tomography - principles and applications. - Rep. Progr. Phys. 66, 239-303.

Flamant, C., P. Drobinski, L. Nance, R. Banta, L. Darby, J. Dusek, M. Hardesty, J. Pelon, E. RICHARD, 2002: Gap flow in an Alpine valley during a shallow south foehn event: Observations, numerical simulations and hydraulic analog. - Quart. J. Roy. Meteor. Soc. 128, 1173-1210.

FrenliCH, R., L. CORNMAN, 2002: Estimating spatial velocity statistics with coherent Doppler lidar. - J. Atmos. Oceanic Technol. 19, 355-366.

FritTs, D.C., C. NAPPO, D.M. Riggin, B.B. BALSLEY, W.E. EICHINGER, R.K. NEWSOM, 2003: Analysis of ducted motions in the stable nocturnal boundary layer during CASES-99. - J. Atmos. Sci. 60, 2450-2472.

Giez, A., G. Ehret, R.L. Schwiesow, K.J. DAVis, D.H. LENSCHOW, 1999: Water Vapor Flux Measurements from Ground-Based Vertically Pointed Water Vapor Differential Absorption and Doppler Lidars. - J. Atmos. Oceanic Technol. 16, 237-250.

Grund, C. J., R. M. Banta, J. L. George, J. N. HowEll, M. J. Post, R. A. Richter, A. M. Weickmann, 2001: High-resolution Doppler lidar for boundary layer and cloud research. - J. Atmos. Oceanic Technol. 18, 376-393.

Hannon, S.M. 2004: Pulsed Doppler lidar for terminal area monitoring of wind and wake hazards. - Proceedings, $11^{\text {th }}$ Conf. on Aviation, Range, and Aerospace Meteor. Paper P4.21. - American Meteor. Soc.

HARDESTY, R.M., L.S. DARBY, 2005: Ground-based and airborne lidar. - Encyclopedia of Hydrologic Sciences. Malcolm G. Anderson(Ed.), Wiley, 697-712.

Harris, M., G.N. Pearson, J.M. Vaughan, D. LetalICK, C. KARLSSON, 1998: The role of laser coherence length in continuous-wave coherent laser radar. - J. Modern Optics 45, 1567-1581.
Harris, M., G. Constant, C. Ward, 2001: Continuouswave bistatic laser Doppler wind sensor. - Appl. Opt. 40, 1501-1506.

Harris, M., M. HAND, A. Wright, 2006: Lidar for Turbine Control. NREL, Golden, Colorado. - Techn. Rep. NREL/TP-500-39154. vi + 47 pp. (available from www.nrel.gov/docs/fy06osti/39154.pdf)

Kelley, N., M. Shirazi, D. Jager, S. Wilde, J. Adams, M. Buhl, P. Sullivan, E. Patton, 2004. Lamar Low-Level Jet Project Interim Report. NREL/TP500-34593. Golden, CO: National Renewable Energy Laboratory, $216 \mathrm{pp}$.

Kelley, N.D., B.J. Jonkman, G.N. Scott, J.T. BialasiewiCZ, L.S. REDMOND, 2005:. The Impact of coherent turbulence on wind turbine aeroelastic response and its simulation. - Windpower, 15-18 May 2005, Denver, Colorado and NREL Report NREL/CP-500-38074. Golden, CO: National Renewable Energy Laboratory.

Kindler, D., A. Oldroyd, A. MacAskill, D. Finch, 2007: An 8 month test campaign of the QinetiQ ZephIR system: preliminary results. - Meteorol. Z. 16, 463-473.

KRISTEnSEN, L. 1999: The perennial cup anemometer. Wind Energy 2, 59-75.

Lenschow, D.H., V.O. Wulfmeyer, C.J. SenfF, 2000: Measuring second- through fourth-order moments in noisy data. - J. Atmos. Oceanic Technol. 17, 1330-1347.

LEVINSON, D.H., R.M. BANTA, 1995: Observations of a terrain-forced mesoscale vortex and canyon drainage flows along the Front Range of the Colorado Rockies. - Mon. Wea. Rev. 123, 2029-2050.

Linné, H., B. Hennemuth, J. Bösenberg, K. Ertel, 2007: Water vapour flux profiles in the convective boundary layer. - Theor. Appl. Climatol. 87, 201-211.

Lothon, M., D.H. Lenschow, S.D. MAYor, 2006: Coherence and scale of vertical velocity in the convective boundary layer from a Doppler lidar. - Bound.-Layer Meteor. 121, 521-536.

Maughan, R.A., Spanton, A.M., M.L. Williams, 1982: An analysis of the frequency distribution of SODAR derived mixing heights classified by atmospheric stability. - Atmos. Environ. 16, 1209-1218.

MEYERS, J.F., 1995: Development of Doppler Global Velocimetry as a flow diagnostics tool. - Meas. Sci. Technol. 6, 769.

NeFF, W.D., R.L. Coulter, 1986: Acoustic remote sensing. - In: D. H. LENSCHOW (Ed.): Probing the Atmospheric Boundary Layer. AMS, Boston, 201-239.

Newsom, R.K., R.M. BAnTA, 2003: Shear-flow instability in the stable nocturnal boundary layer as observed by Doppler lidar during CASES-99. - J. Atmos. Sci. 30, 1633.

Newsom, R.K., D. Ligon, R.J. Calhoun, R. Heap, E. Cregan, M. Princevac, 2005: Retrieval of microscale wind and temperature fields from single- and dual-Doppler lidar data. - J. Appl. Meteor. 44, 1324-1345.

Pichugina, Y.L., R.M. BAnta, N.D. Kelley, S.P. SANDBERG, J.L. MACHOL, W.A. BREWER, 2004: Nocturnal low-level jet characteristics over southern Colorado. $-16^{\text {th }}$ Symposium on Boundary Layers and Turbulence, 913 August, 2004 Portland, Maine. 
Pichugina, Y.L., R.M. Banta, N.D. Kelley, 2005: Application of high-resolution Doppler lidar data for wind energy assessment. - Paper 6.4 (CD), $2^{\text {nd }}$ Symposium on Lidar Atmospheric Applications, 85th AMS Annual Meeting, 9-13 January 2005, San Diego., CA.

Pichugina, Y.L., R. M. Banta, N. D. Kelley, 2007: Analysis of the southern Colorado low-level jet by highresolution Doppler lidar data: Comparisons to the Great Plains LLJ climatologies. - Preprints, Third Symposium on Lidar Atmospheric Applications, San Antonio, American Meteorological Society, Boston MA, USA.

Pichugina Y.L., R. M. Banta, W. A. Brewer, N. D. Kelley R. K. Newsom, S.C. TuCKER, submitted. Evaluation of the sensitivity of Doppler-based horizontal velocity and turbulence profiles to averaging procedures. - J. Atmos. Oceanic Technol.

Post, M.J., R.E. CUPP, 1990: Optimizing a pulsed Doppler lidar. - Appl. Opt. 29, 4145-4158.

Poulos, G.S., W. Blumen, , D.C. Fritts, J.K. Lundquist, J. Sun, S. Burns, C. NAPPO, R.M. Banta, R.K. Newsom, J. CUXART, E. Terradellas, B. BAlsley, M. Jensen, 2002: CASES-99: A comprehensive investigation of the stable nocturnal boundary layer. - Bull. Amer. Meteor.. Soc. 83, 555-581.

SMALIKHO, I.N., F. KÖPP, S. RAHM, 2005: Measurement of atmospheric turbulence by $2-\mu \mathrm{m}$ Doppler lidar. - J. Atmos. Oceanic Technol. 22, 1733-1746.

SMith, D.A., M HARRIS, A S COFFEY, T MiKKELSEN, H.E. Jørgensen, J. MAnn, R. DAnielian, 2006: Wind lidar evaluation at the Danish wind test site in Høvsøre. Wind Energy 9, 87-93.
Sun, J., Sean P. Burns, Donald H. Lenschow, R. Banta, R. Newsom, R. Coulter, S. Frasier, T. Ince, C. Nappo, J. CuXart, W. Blumen, X. Lee, X.Z. HU, 2002: Intermittent turbulence associated with a density current passage in the stable boundary layer. - Bound.Layer Meteor. 105, 199-219.

Sun, J., D. Lenschow, S. Burns, R. Banta, R. NewSom, R. Coulter, S. Frasier, T. Ince, C. Nappo, B. Balsley, M. Jensen, L. Mahrt, D. Miller, B. SKELLY, 2004: Intermittent turbulence in stable boundary layers and the processes that generate it. - Bound-Layer Meteor. 110, 255-279.

VDI 3786 Blatt 14, 2001: Environmental Meteorology, Ground-based remote sensing of the wind vector - Doppler wind LIDAR. - Beuth Verlag, Berlin. 48 pp.

Vogt, S., A. WIESER, 2006: Doppler Wind Lidar and Radar Wind Profiler - Comparison of Instruments and Discussion of Various Measurement Methods. - Extended Abstracts of the Intern. Symp. for the Advancement of Boundary Layer Remote Sensing (ISARS 13), 18-20 July 2006, GarmischPartenkirchen, Germany. Wiss. Ber. FZKA 7222, 53-55.

Weissmann, M.D., G.J. Mayr, R.M. BAnTA, A. Gohm, 2004: Observations of the temporal evolution and spatial structure of the gap flow in the Wipp Valley on 2 and 3 October 1999. - Mon. Wea. Rev. 132, 2684-2697.

Wulfmeyer, V.O., RANDALl, M., BREWER, W. A., R.M HARDESTY, 2000: $2 \mu \mathrm{m}$ Doppler lidar transmitter with high frequency stability and low chirp. - Opt. Lett. 25, 1228-1230. 